\title{
A presença do filme nacional nas salas de cinema do Brasil: um estudo sobre a codistribuição
}

\author{
Fernando Antonio Prado Gimenez' \\ Daniela Torres da Rocha' \\ I - UFPR \\ Curitiba (PR), Brasil
}

Resumo: O mercado de cinema no Brasil tem apresentado uma dinâmica de crescimento nos últimos anos. Recentemente, a codistribuição, i.e., a distribuição de um filme feita por duas ou mais empresas ao mesmo tempo tem sido uma estratégia mais frequente. O objetivo deste artigo é analisar as diferentes formas de atuação no mercado de codistribuição de filmes brasileiros. Utilizaram-se dados secundários disponíveis no Observatório do Cinema e Audiovisual, referentes aos anos de 2009 a 2015. Nesse período foram encontradas 203 empresas distribuidoras atuando no mercado. Nesse conjunto, apenas 29 atuaram em codistribuição de filmes. Os dados foram analisados por meio da Análise de Agrupamentos. Foram identificadas cinco formas distintas de atuação estratégica na codistribuição do cinema brasileiro.

Palavras-chave: cinema brasileiro; mercado; distribuição.

Abstract: The presence of national film at cinema rooms in Brazil: a study about co-distribution The Brazilian film market has shown a growth momentum last years. Recently, co-distribution, i.e., the distribution of a film made by two or more companies at the same time, has been a more frequent strategy. The aim of this paper is to analyze the different ways of acting in the co-distribution of Brazilian films. The analysis was based on secondary data available at the Observatório do Cinema e Audiovisual for 2009 to 2015. During this period, there were 203 distribution companies operating in the market. In this set, only 29 participated in co-distribution of films. The data were analyzed through Cluster Analysis. Five distinct forms of strategic action were identified in the co-distribution of Brazilian cinema.

Keywords: Brazilian cinema; marketplace; distribution.

\section{Introdução}

O mercado de cinema no Brasil tem apresentado uma dinâmica de crescimento nos últimos anos. Esse crescimento se manifestou em termos de público e renda nas salas 
de cinema brasileiras, bem como no número de salas que, entre 2009 e 2015, passou de 2.110 para 3.005. A renda de bilheteria e o volume de público cresceram a taxas anuais médias de $9 \%$ e $8 \%$, respectivamente, conforme dados disponibilizados pelo Observatório Brasileiro do Cinema e do Audiovisual (oca.ancine.gov.br), que é mantido pela Agência Nacional do Cinema - ANCINE.

Nos últimos sete anos, com base em informações do Observatório Brasileiro do Cinema e do Audiovisual, foram distribuídos no mercado 4.210 filmes por um número crescente de distribuidoras. Em 2009, 54 empresas distribuíram 588 filmes, entre os quais 317 foram lançados naquele ano, sendo os demais filmes já exibidos em anos anteriores. Os números relativos a 2015 demonstram que o número de distribuidoras chegou a 85 e o de filmes a 785, dos quais 446 foram lançamentos novos. No conjunto de sete anos, os filmes exibidos alcançaram uma renda de bilheteria de R\$11,35 bilhões com um público de 1,01 milhão de pessoas.

A participação do cinema nacional no mercado exibidor oscilou entre um mínimo de 10,68\% (2012) e um máximo de 19,05\% (2010) do público total. Em termos de participação na renda de bilheteria, a participação do cinema brasileiro teve seu menor valor em 2012 (9,8\%), e o pico em 2010 com 17,93\%. Na média dos sete anos, a participação do cinema nacional em público foi de $14,23 \%$ e de $12,98 \%$ em bilheteria.

Há muitos anos o mercado de cinema no Brasil é dominado pela produção oriunda dos Estados Unidos. Na última edição do Anuário Estatístico do Cinema Brasileiro (ANCINE, 2015), por exemplo, informa-se que $83,9 \%$ do público dos lançamentos foi para filmes dos Estados Unidos; 10,6\% do Brasil; 2,0\% da França; 1,4 \% da Alemanha; e 2,1\% de outros países. Esta participação na bilheteria do cinema dos Estados Unidos é altamente desproporcional em relação à participação no número de filmes lançados. No mesmo ano, a participação dos Estados Unidos em lançamentos foi de 37,5\%, do Brasil chegou a 29,5\%, a França teve 9,6\%, Reino Unido com 2,3\% e outros países com 21,2\%.

Essa situação de mercado é reflexo da forte presença de seis distribuidoras internacionais - Fox, Disney, Warner, Paramount, Sony e Universal - que distribuem principalmente os filmes produzidos nos Estados Unidos. Em 2014, as seis empresas conseguiram 72,3\% do público dos lançamentos, com a ocupação de 63,2\% das salas de exibição, renda de 73,3\% do total e, apenas, 21,7\% dos filmes lançados (ANCINE, 2015).

No que diz respeito às distribuidoras brasileiras, que em geral são as responsáveis pela distribuição da maior parte da produção cinematográfica nacional, se observa que, embora o número de empresas tenha crescido ao longo desses anos, bem como o número de filmes brasileiros lançados, a participação das distribuidoras brasileiras em termos de market share ficou em $27,34 \%$ da bilheteria e 28,57\% do público total. Algumas distribuidoras brasileiras também atuam com filmes estrangeiros. Isso explica o fato da participação destas em bilheteria e público ser maior do que a do cinema nacional.

Um aspecto que tem se revelado mais forte nos últimos anos é a codistribuição do cinema brasileiro, i.e., a distribuição de um filme feita por duas ou mais empresas 
ao mesmo tempo. Entre 2009 e 2014, foram lançados 713 filmes brasileiros, sendo que $135(11,50 \%)$ foram distribuídos por duas ou três empresas em parceria. Ao longo dos anos, com o crescimento do número de filmes brasileiros lançados no mercado, se observa um crescimento no número de codistribuições. Em 2009, foram apenas 10 filmes codistribuídos, sendo que, em 2015, atingiu-se a marca de 28 filmes. Em termos percentuais, isso significou uma passagem de 5,70\% dos filmes lançados em 2009 para 13,40\% dos filmes de 2014. 2013 foi o ano em que essa proporção foi maior, tendo atingido 15,00\% dos 129 filmes brasileiros lançados naquele ano.

Este fenômeno pode ser visto, também, na produção de filmes brasileiros. A análise das informações disponibilizadas pelo Observatório Brasileiro do Cinema e do Audiovisual, evidenciou um aumento no número de coproduções de filmes brasileiros entre 2009 e 2015. Os anos de 2013 e 2014 representaram 75,30\% das coproduções brasileiras lançadas no cinema, com 41 e 13 filmes, respectivamente. Em 2015, foram 12 filmes coproduzidos, representando 9,30\% dos filmes lançados neste ano. Isto significa que, nos últimos três anos, foram coproduzidos 84 filmes, 22,58\% dos filmes brasileiros lançados no triênio.

Nesse contexto de ampliação de parcerias tanto na produção quanto na distribuição de filmes brasileiros, o objetivo desse artigo é analisar as diferentes formas de atuação no mercado de codistribuição de filmes brasileiros. Para cumprir essa finalidade e aprofundar a identificação de tipos de estratégias de codistribuição, o artigo está dividido em mais quatro seções, além dessa introdução. Na próxima seção discorre-se sobre a questão da distribuição de filmes brasileiros na chamada primeira janela, isto é, as salas de cinema. Na seção seguinte, é feita uma descrição dos procedimentos adotados na análise da codistribuição do cinema brasileiro entre 2009 e 2015. Na quarta seção são apresentados os resultados do estudo. Por fim, encerra-se o artigo com as considerações finais em que se apontam a principais contribuições do estudo, suas limitações e sugestões de estudos futuros.

\section{A questão da distribuição do filme nacional}

A convergência transmidiática que está ocorrendo no campo da produção de cinema e do audiovisual tem acarretado mudanças no mercado cinematográfico (BAHIA; AMÂNCIO, 2010). Essas mudanças causam uma reorganização da relação entre cinema e televisão, com um crescimento da presença do filme em outras mídias, além das salas de cinema. No entanto, a exibição de filmes em salas de cinema ainda é parte importante da estratégia das empresas distribuidoras.

Analisando a evolução da produção cinematográfica brasileira desde 1995, Borges (2015, p. 198) comentou que "a audiência ao filme brasileiro ainda é bem reduzida se comparada à dos filmes norte-americanos, o que indica que a obra nacional não tem sido distribuída e exibida de forma suficiente a alcançar o público". Esta questão já fora ressaltada por Bahia (2012, p. 128) que sugere que tanto distribuição como exibição 
"não absorvem o crescimento do número de títulos nacionais produzidos. O mercado incorpora poucos filmes brasileiros, concentrando-se naqueles cuja visão é mais comercial". Disso, segundo a autora, resulta que o crescimento da produção nacional não é seguido pelo público brasileiro em função tanto de aspectos internos à atividade cinematográfica quanto a mudanças tecnológicas associadas a novos modos de consumo do produto audiovisual, substituindo as salas de cinema.

Autran (2009) comentou que, apesar da política de fomento via incentivos fiscais ter contribuído para um crescimento no número de filmes produzidos no Brasil, não houve alteração significativa da participação do cinema nacional na venda de ingressos no mercado exibidor, pelo menos até 2004, ano em que se encerrou a análise efetuada.

Estes problemas incipientes se conjugam a uma agressividade competitiva acentuada das empresas dominantes do setor. Ikeda (2012) comentou sobre a existência de uma rede de produção e distribuição em escala mundial, compostas pelas majors norte-americanas dominando o mercado cinematográfico na mesma escala, devido a sua capilaridade de envolvimento em atividades de distribuição em larga escala. Para o autor, o caso brasileiro, nos anos mais recentes, exemplifica essa dominação, pela invasão maciça dos produtos de "Hollyworld" - filmes em língua inglesa de grandes orçamentos e uma mídia em escala mundial - exibidos nos cinemas brasileiros com mais de 500 cópias, ..., pela participação ativa na coprodução de filmes brasileiros de grande potencial de bilheteria... produzidos seja por um apoio indireto do Estado, através de um mecanismo de renúncia fiscal...; seja por uma aliança com as oligarquias locais, através de acordos comerciais com a TV Globo, através da Globo Filmes, promovendo apoio de mídia, cedendo seu "star system" e acrescentando um “tempero nacional" às produções (IKEDA, 2012, p. 79).

Michel e Avelar (2012) afirmaram que as empresas distribuidoras procuram aumentar sua renda pela exploração de filmes que tenham maior público. Em função da presença dominante do cinema norte-americano, os autores consideram que o filme brasileiro não consegue encontrar todas as possibilidades de mercado. Comparando as distribuidoras nacionais com as estrangeiras, perceberam que estas têm um market share muito maior do que as primeiras. Ao mesmo tempo, os filmes de maior renda são distribuídos pelas maiores empresas. Por outro lado, filmes de menor potencial são distribuídos por distribuidoras menores ou mais novas no mercado.

Por outro lado, Ruy (2009), evidenciou que os filmes brasileiros de maiores bilheterias entre 2003 e 2008 tiveram, em sua distribuição, a participação de agentes de grande poder financeiro e recursos de mídia. Todos os filmes foram distribuídos pelas majors. Mas, parece que essa é uma realidade presente, também, no mercado dos Estados Unidos. Pangarker e Smit (2013) investigaram o efeito de oito variáveis sobre receita de bilheteria no mercado americano e internacional em uma amostra de 289 filmes americanos lançados em 2009 e 2010. Os resultados demonstraram que custos de produção, distribuição 
por uma das majors, indicações para o Oscar e sequências de outros filmes foram os principais influenciadores de bilheteria. Por outro lado, gênero do filme, data de lançamento em período de férias ou feriados e críticas positivas não tiveram influência significativa sobre a renda total de bilheteria obtida no mercado americano e internacional.

O domínio global dos filmes produzidos em Hollywood é associado a um movimento de internacionalização das majors. Scott (2004) afirmou que os mercados de exportação desses filmes expandiram muito tanto em função de iniciativas estratégicas dos atores da indústria quanto pelo apoio do governo dos Estados Unidos. Por outro lado, conforme registrou Matta (2010), do lado das políticas públicas brasileiras, houve uma ineficácia no apoio à distribuição, redundando em maiores desvantagens competitivas para o produto audiovisual brasileiro ocupar espaços nas salas de cinema.

Uma questão que pode afetar a atuação das distribuidoras é a acelerada digitalização das salas de cinema. Esta tecnologia permite uma exibição dos filmes em um grande número de salas com um custo muito menor do que o sistema anterior, o que pode até diminuir o espaço de atuação das distribuidoras conforme apontado por Simis (2015). Eliashberg, Elberse e Leenders (2006) indicaram, também, os riscos da pirataria digital como uma ameaça ao desempenho das distribuidoras. No entanto, ao mesmo tempo, sugeriram que os benefícios da tecnologia digital seriam maiores que os custos, pelo menos em um futuro previsível.

Entre 2009 e 2015, o número de distribuidoras que atuaram no Brasil elevou-se de 54 para 85 empresas. Esse crescimento no número de empresas que operam na distribuição foi acompanhando pelo aumento no número de filmes exibidos anualmente, que passou de 588, em 2009, para 785, em 2015. Os dados sobre o número de filmes brasileiros revelam um crescimento, também, mas em menor volume. Em 2009, foram exibidos 175 filmes produzidos no Brasil, enquanto que em 2015, esse número chegou a 209. Ou seja, um crescimento de 19,43\%, menor do que o crescimento no número de distribuidoras $(57,41 \%)$ e do número de filmes (33,50\%). Em termos de número de filmes, os estrangeiros representaram $72,18 \%$ do total no período. A tabela 1 sintetiza esses dados.

\begin{tabular}{|l|l|l|l|l|}
\hline \multicolumn{1}{|c|}{ Ano } & \multicolumn{1}{c|}{ Distribuidoras } & \multicolumn{1}{c|}{ Filmes } & \multicolumn{1}{c|}{ Estrangeiros } & \multicolumn{1}{c|}{ Brasileiros } \\
\hline 2009 & 54 & 588 & 413 & 175 \\
\hline 2010 & 52 & 510 & 373 & 137 \\
\hline 2011 & 59 & 562 & 395 & 167 \\
\hline 2012 & 76 & 515 & 379 & 136 \\
\hline 2013 & 85 & 573 & 406 & 167 \\
\hline 2014 & 75 & 677 & 497 & 180 \\
\hline 2015 & 85 & 785 & 576 & 209 \\
\hline Total & 203 & 4210 & 3039 & 1171 \\
\hline
\end{tabular}

Tab. 1. Número de distribuidoras e filmes exibidos - 2009/2015.

Fonte: Elaborado pelos autores com base em dados do Observatório do Cinema e Audiovisual (www.oca.ancine.gov.br). 
No mercado exibidor, os filmes anualmente se compõem por aqueles lançados em anos anteriores e os filmes lançados no ano. A tabela 2 apresenta os dados referentes somente aos filmes lançados em cada ano. O número de lançamentos estrangeiros foi crescente a cada ano, exceto em 2010, quando caiu 4,42\% em relação a 2009. Os filmes brasileiros, no entanto, tiveram um comportamento mais irregular, com decréscimo em relação ao ano anterior em 2010, 2012 e 2014. De novo, os filmes estrangeiros foram a maioria dos lançamentos no período, atingindo $71,71 \%$ do total. Por fim, os filmes brasileiros codistribuídos, conforme comentado anteriormente tiveram um crescimento maior nesse período, passando de apenas 10 em 2009 para 28 em 2015. No total, representaram $18,93 \%$ dos filmes nacionais lançados no período.

\begin{tabular}{|l|l|l|l|l|}
\hline \multicolumn{1}{|c|}{ Ano } & \multicolumn{1}{|c|}{ Lançamentos } & \multicolumn{1}{c|}{ Estrangeiros } & \multicolumn{1}{c|}{ Brasileiros } & \multicolumn{1}{c|}{ Codistribuições } \\
\hline 2009 & 317 & 233 & 84 & 10 \\
\hline 2010 & 303 & 229 & 74 & 16 \\
\hline 2011 & 337 & 237 & 100 & 14 \\
\hline 2012 & 327 & 244 & 83 & 16 \\
\hline 2013 & 397 & 268 & 129 & 25 \\
\hline 2014 & 393 & 279 & 114 & 26 \\
\hline 2015 & 446 & 317 & 129 & 28 \\
\hline 2016 & 2520 & 1807 & 713 & 135 \\
\hline
\end{tabular}

Tab. 2. Lançamentos anuais - 2009/2015.

Fonte: Elaborado pelos autores com base em dados do Observatório do Cinema e Audiovisual (www.oca.ancine.gov.br).

A participação no mercado, em termos de público e renda, para os três tipos de filmes, é demonstrada nos gráficos 1 e 2. Em termos de público, fica visível o domínio dos filmes estrangeiros nas salas de cinema do Brasil. O gráfico 1 demonstra, também, que os filmes brasileiros codistribuídos têm aumentado sua participação no total de público dos filmes brasileiros. O mesmo comportamento pode ser visto no gráfico 2 que apresenta a evolução para a renda de bilheteria.

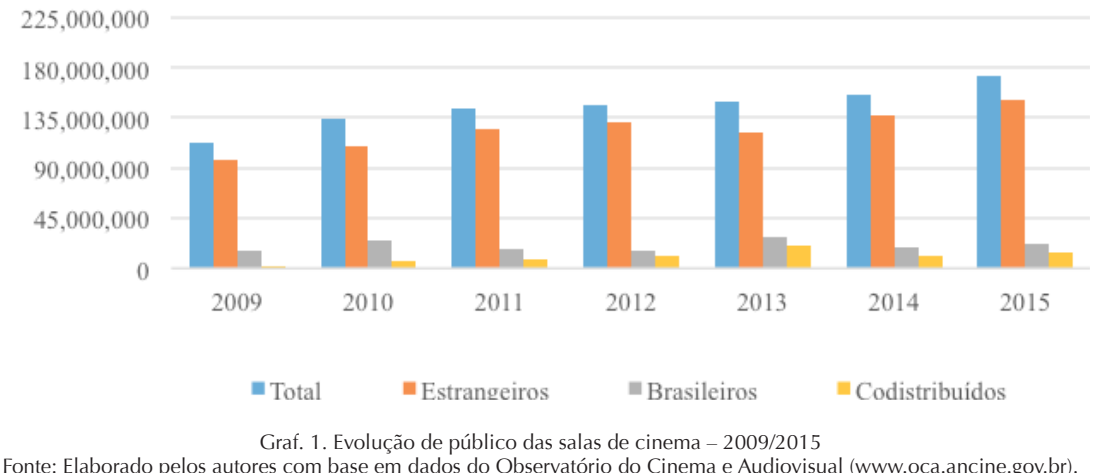

Fonte: Elaborado pelos autores com base em dados do Observatório do Cinema e Audiovisual (www.oca.ancine.gov.br). 
$3,000,000,000.00$

$2,250,000,000.00$

$1,500,000,000.00$

$750,000,000.00$

0.00

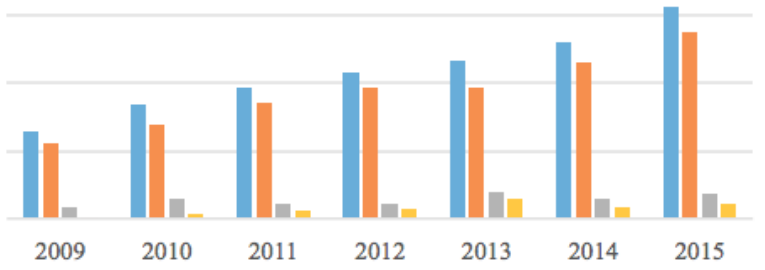

" Total Estrangeiros $=$ Brasileiros $=$ Codistribuídos

Graf. 2. Evolução de renda de bilheteria das salas de cinema - R\$ - 2009/2015

Fonte: Elaborado pelos autores com base em dados do Observatório do Cinema e Audiovisual (www.oca.ancine.gov.br).

A dinâmica do mercado exibidor de filmes no Brasil nesse período demonstra que a estratégia de codistribuição está sendo cada vez mais adotada, mas por um conjunto ainda pequeno de empresas do setor. Todavia, os dados indicam que esta estratégia está associada a um desempenho cada vez melhor em termos de público e renda de bilheteria. Conforme evidenciado na tabela 3, a proporção de número de filmes, público e renda de bilheteria da codistribuição avançou de forma acentuada nesse período. Em 2009 foram $11,90 \%$ dos filmes brasileiros, representando $14,86 \%$ do público e 15,93\% da bilheteria. Ao final do período, estes números chegaram a 21,71\% dos filmes, 62,17\% do público e $61,29 \%$ da renda.

\begin{tabular}{|l|l|l|l|}
\hline \multicolumn{1}{|c|}{ Ano } & \multicolumn{1}{|c|}{ Filmes (\%) } & \multicolumn{1}{c|}{ Público (\%) } & Renda de Bilheteria (\%) \\
\hline 2009 & 11,90 & 14,86 & 15,93 \\
\hline 2010 & 21,62 & 25,90 & 25,48 \\
\hline 2011 & 14,00 & 49,57 & 49,55 \\
\hline 2012 & 19,28 & 67,46 & 67,71 \\
\hline 2013 & 19,38 & 75,60 & 75,85 \\
\hline 2014 & 22,81 & 59,33 & 59,03 \\
\hline 2015 & 21,71 & 62,17 & 61,29 \\
\hline Total & 18,93 & 51,69 & 53,74 \\
\hline
\end{tabular}

Tab. 3. Participação da codistribuição no número de filmes, público e renda de bilheteria - 2009-2015. Fonte: Elaborado pelos autores com base em dados do Observatório do Cinema e Audiovisual (www.oca.ancine.gov.br).

A codistribuição pode ser vista como uma aliança estratégica. Conforme Yoshino e Rangan (1996, p. 4-5), uma aliança estratégica é uma parceria comercial que aumenta a eficácia das estratégias competitivas das organizações participantes, baseada no intercâmbio de tecnologias, qualificações, produtos ou serviços. Uma característica 
marcante das alianças é que as empresas, ao cooperarem, permanecem independentes, podendo até competir em outras atividades. Assim, o presente texto descreve características do uso de alianças estratégicas no campo da distribuição do cinema brasileiro. Para isso, foram utilizados os procedimentos descritos na próxima seção.

\section{Procedimentos do estudo}

Para realizar a análise do mercado de codistribuição do cinema brasileiro foram utilizados dados secundários disponíveis no Observatório do Cinema e Audiovisual. Desde 2009, são fornecidas estatísticas sobre a distribuição dos filmes nas salas de cinema localizadas no território brasileiro. Estes dados são compilados a partir de informações prestadas pelas próprias empresas distribuidoras ao Sistema de Acompanhamento da Distribuição em Salas de Exibição (SADIS) da Agência Nacional de Cinema.

Os dados são informados anualmente e classificam as empresas distribuidoras em um ranking por títulos exibidos, público total e renda total. Para cada um dos anos com dados disponíveis (2009 a 2015), foram identificadas as empresas distribuidoras que atuaram de forma independente e em codistribuição. Nesse período foram encontradas 203 empresas distribuidoras atuando no mercado. Nesse conjunto, apenas 29 atuaram em codistribuição de filmes.

Para o conjunto de empresas que fizeram codistribuição, foi construída uma base de dados com as seguintes variáveis: número de anos em que codistribuiu filmes; número de filmes distribuídos; número de filmes brasileiros distribuídos (independentemente e em codistribuição); público e renda total; público e renda com filmes brasileiros sem codistribuiçãa; público e renda com filmes brasileiros codistribuídos. Estas variáveis foram utilizadas para identificar grupos de empresas que pudessem refletir diferentes padrões de atuação no mercado exibidor brasileiro.

A identificação dos grupos de empresas foi feita por meio da Análise de Agrupamentos (Cluster Analysis). A análise de agrupamentos é uma técnica estatística que possui o objetivo de classificar uma amostra de entidades (indivíduos ou objetos) em um determinado número de grupos mutuamente excludentes, com base nas similaridades entre as entidades (HAIR JR. Et al., 2005). Optou-se por utilizar a divisão da amostra em cinco grupos usando o método de aglomeração Ward e como dissimilaridade a distância euclidiana. Esta divisão mostrou-se adequada porque os grupos gerados apresentam-se mais heterogêneos do que as demais situações. Ressalta-se que antes de realizar a análise de agrupamentos optou-se em padronizar as variáveis, uma vez que estas apresentaram diferentes unidades de medidas.

\section{As formas de atuação na codistribuição do filme brasileiro}

Os resultados da análise realizada indicaram a existência de cinco agrupamentos. Estes podem ser visto como formas distintas de atuação no mercado de codistribuição 
do filme brasileiro internamente. Entre as 29 empresas que foram identificadas com participação em codistribuição de filmes nacionais, apenas quatro são ligadas às majors de Hollywood (Fox, Sony, Warner e Universal). Disney e Paramount não atuaram dessa forma entre 2009 e 2015. O quadro 1 apresenta a composição dos agrupamentos encontrados.

\begin{tabular}{|l|l|}
\hline Grupo & Integrantes \\
\hline 1 & $\begin{array}{l}\text { Internacional: Fox. } \\
\text { Nacional: Imagem. }\end{array}$ \\
\hline 2 & Internacional: Sony; Warner; Universal. \\
\hline 3 & Nacional: Paris; Downtown \\
\hline 4 & $\begin{array}{l}\text { Nacional: RioFilme; Europa; Imovision; Espaço Filmes; } \\
\text { Videofilmes; Polifilmes. }\end{array}$ \\
\hline 5 & $\begin{array}{l}\text { Nacional: H2O Films; Elo Company; Mobz; Serendip; Ab Filmes; } \\
\text { Conspiração; Bretz Vídeo; Film Connection; Nossa Distribuidora; } \\
\text { Art Films; Ideias Ideais; Festival Filmes; Lapfilme; Plateau Filmes; } \\
\text { Topázio Filmes; Asacine. }\end{array}$ \\
\hline
\end{tabular}

Quad. 1.Agrupamentos de empresas codistribuidoras do filme brasileiro - 2009/2015. Fonte: Elaborado pelos autores.

O primeiro grupo é composto por duas empresas: Fox e Imagem. A primeira é uma das majors e a segunda é uma das distribuidoras nacionais com maior presença no mercado brasileiro no período analisado. A Fox foi a empresa de maior participação na renda de bilheteria nesses sete anos, com um faturamento de R\$1.983.917.798,00, equivalente a $17,50 \%$ da bilheteria no período. Este resultado foi fruto da distribuição de 228 filmes, dos quais 35 eram brasileiros e apenas um foi codistribuído. A Imagem foi a segunda empresa nacional em termos de renda de bilheteria. No cômputo geral de distribuidoras que atuaram no período ela ocupou a oitava posição com renda de bilheteria de $\mathrm{R} \$$ 643.785.795,30, equivalente a 5,67\% de market share. Este resultado foi obtido com a distribuição de 275 títulos, sendo 53 brasileiros com três codistribuições. As duas empresas representaram $21,17 \%$ do mercado em termos de bilheteria.

O segundo grupo é integrado por três majors: Sony, Warner e Universal. As três empresas ocuparam a segunda, quarta e sétima posições, respectivamente, em termos de renda de bilheteria, representando 33,18\% do mercado. A Sony distribuiu 273 filmes (57 brasileiros; 13 codistribuições), a Warner fez a distribuição de 198 filmes (22 brasileiros; 2 codistribuições) e a Universal teve 132 filmes distribuídos (12 brasileiros; 1 codistribuição). Em relação ao grupo anterior, são mais atuantes em codistribuição. No entanto, esta estratégia contribui muito pouco para a atuação das duas empresas no mercado.

O terceiro grupo foi formado por duas empresas brasileiras: Paris e Downtown. A Paris é a empresa nacional de maior participação em renda de bilheteria ( $\mathrm{R}$ 1.216.609.825,24; $10,72 \%$ ) e ocupa a sexta posição na classificação geral. Essa empresa fez a distribuição 
de 346 filmes, dos quais 71 eram brasileiros, a maioria em codistribuição (90,14\%). A Downtown é a terceira empresa na classificação entre as nacionais e a nona, em termos de renda de bilheteria, no ranking geral. Sua participação na bilheteria do período foi de R\$ 318.870.061,70 (2,81\%). Esse resultado foi alcançado com a distribuição de 112 filmes, todos brasileiros, sendo majoritariamente codistribuídos (75,89\%). As duas empresas atuaram em parceria de forma intensiva nesses sete anos, com a codistribuição de 56 filmes entre 2010 e 2015. Apenas em 2009, as duas empresas não fizeram aliança na distribuição de filmes.

O quarto grupo, integrado por seis empresas nacionais, codistribuiu 83 filmes brasileiros, de um total de 330 filmes. Essas empresas também fizeram distribuição de filmes estrangeiros, 484. Ou seja, 59,46\% de sua atuação no mercado. O grupo foi responsável por apenas $2,05 \%$ da renda de bilheteria nos setes ano, o que indica ser composto majoritariamente por empresas menores.

Por fim, o quinto grupo, também composto por empresas menores brasileiras distribuiu 169 títulos, sendo 79 brasileiros, e a maioria em codistribuição (64,58\%). O market share desse grupo foi ainda menor em comparação com o anterior, 0,66\%.

Na tabela 4 apresenta-se um conjunto de indicadores que foram utilizados para a distinção dos cinco grupos em termos de atuação na codistribuição de filmes brasileiros. Estes indicadores são: tempo de atuação na codistribuição no período (TC); número de filmes codistribuídos (FC); percentual de filmes codistribuídos em relação aos filmes brasileiros distribuídos (FC/FB); percentual de filmes codistribuídos em relação ao total de filmes distribuídos (FC/FT); percentual de público dos filmes codistribuídos sobre público dos filmes brasileiros (PFC/PFB); percentual do público dos filmes codistribuídos sobre público total dos filmes (PFC/PFT); percentual da renda com filmes codistribuídos sobre renda com filmes brasileiros (RFC/RFB); e, percentual da renda com filmes codistribuídos sobre renda total obtida (RFC/RFT). Os indicadores foram calculados para cada empresa integrantes dos grupos e os números representam os valores médios para cada grupo.

\begin{tabular}{|l|l|l|l|l|l|l|l|l|l|}
\hline Grupo & $\begin{array}{c}\text { TC } \\
\text { (anos) }\end{array}$ & $\begin{array}{c}\text { FC } \\
\text { (filmes) }\end{array}$ & $\begin{array}{c}\text { FT } \\
\text { (filmes) }\end{array}$ & $\begin{array}{c}\text { FC/FB } \\
(\%)\end{array}$ & $\begin{array}{c}\text { FC/FT } \\
(\%)\end{array}$ & $\begin{array}{c}\text { PFC/PFB } \\
(\%)\end{array}$ & $\begin{array}{c}\text { PFC/PFT } \\
(\%)\end{array}$ & $\begin{array}{c}\text { RFC/RFB } \\
(\%)\end{array}$ & $\begin{array}{c}\text { RFC/RFT } \\
(\%)\end{array}$ \\
\hline 1 & 7,00 & 2,00 & 251,00 & 4,26 & 0,76 & 8,97 & 1,92 & 9,11 & 1,76 \\
\hline 2 & 7,00 & 5,00 & 201,00 & 13,41 & 2,18 & 22,38 & 0,84 & 23,94 & 0,76 \\
\hline 3 & 7,00 & 74,00 & 229,00 & 83,02 & 47,19 & 97,33 & 61,95 & 97,70 & 61,99 \\
\hline 4 & 7,00 & 14,00 & 136,00 & 26,13 & 21,66 & 33,34 & 26,72 & 34,27 & 27,43 \\
\hline 5 & 2,31 & 2,00 & 11,00 & 68,93 & 59,04 & 78,80 & 63,69 & 75,00 & 57,91 \\
\hline
\end{tabular}

Tab. 4. Indicadores de atuação na codistribuição de filmes brasileiros - 2009/2015. Fonte: Elaborado pelos autores.

A importância da codistribuição de filmes brasileiros na atuação dos grupos identificados varia significativamente entre eles. Pode-se perceber pela análise dos dados que, para o grupo 3, formado por Paris e Downtown, a codistribuição é a forma mais 
dominante de atuação no mercado para as duas empresas. Elas têm a maior média de filmes codistribuídos no período, e têm os maiores percentuais em termos de renda de bilheteria e público oriundos de filmes codistribuídos. No caso dos filmes brasileiros, as duas empresas obtêm mais de $97 \%$ de público e bilheteria com filmes codistribuídos. No seu esforço total de distribuição de filmes, as duas empresas atingiram mais de $60 \%$ de público e bilheteria com as codistribuições.

Outro grupo em que a codistribuição têm papel relevante no desempenho das empresas tanto em termos de público quanto de bilheteria é o grupo 5. Este grupo é formado por empresas mais jovens, média de atuação de 2,31 anos em codistribuição, e menores, com média de onze filmes distribuídos no período. Para este grupo, a participação do público e renda de bilheteria obtida com filmes codistribuídos atingiu mais de $70 \%$ do obtido com filmes brasileiros, e em torno de $60 \%$ do obtido com todos os filmes distribuídos. Isto sugere que, para as empresas entrantes no mercado distribuidor de cinema do Brasil, a aliança com outras empresas é uma estratégia muito adotada.

Para as empresas internacionais, que se dividiram entre os grupos 1 e 2, a estratégia de codistribuição não tem um papel central em sua atuação no mercado como um todo. No caso do grupo, formado por Sony, Warner e Universal, os filmes brasileiros codistribuídos representam pouco mais de $2 \%$ do total de filmes exibidos nos sete anos com participação na geração de público e bilheteria abaixo de 1\%. No grupo 1, formado pela Fox e a Imagem, embora o número de filmes codistribuídos seja ainda menor, as suas contribuições para público e bilheteria são um pouco maiores, atingindo $1,92 \%$ e $1,76 \%$, respectivamente. Isso pode sugerir que estas empresas se envolvem na codistribuição de filmes brasileiros com maior potencial de mercado.

Na tentativa de aprofundar o detalhamento do perfil dos grupos identificados, fez-se uma análise da presença dessas empresas, em parcerias de codistribuição, nos filmes de maior bilheteria do período. Para isso, foi utilizada a classificação dos filmes brasileiros lançados entre 1995 e 2015 disponível em http://oca.ancine.gov.br/filmes_bilheterias. htm. No período todo foram 1252 filmes. Entre 2009 e 2015, o total de filmes brasileiros lançados chegou a 713 filmes. Desse conjunto, foram analisados os dados dos 150 filmes com maior bilheteria.

O primeiro resultado encontrado foi que $40 \%$ dos filmes brasileiros de maior bilheteria nesse período chegaram ao mercado por meio de parcerias entre duas ou mais empresas. São 60 filmes codistribuídos entre os de maior bilheteria, o que significa $44,44 \%$ do total de filmes codistribuídos entre 2009 e 2015. A tabela 5 apresenta os dados para cada aliança entre empresas distribuidoras que estiveram entre os filmes de maior bilheteria nesse período. 


\begin{tabular}{|c|c|c|c|c|}
\hline Distribuidora & Filmes & $\begin{array}{l}\text { Máximo de Salas } \\
\text { (Média) }\end{array}$ & Renda (R\$) & Público \\
\hline Downtown/Paris & 28 & 378 & $448.938 .052,57$ & 39.830 .082 \\
\hline $\begin{array}{l}\text { Downtown/Paris/ } \\
\text { Riofilme }\end{array}$ & 8 & 376 & $172.183 .885,75$ & 17.076 .807 \\
\hline Sony/Downtown & 3 & 261 & $36.822 .668,46$ & 4.108 .470 \\
\hline $\begin{array}{l}\text { Europa Filmes/ } \\
\text { RioFilme }\end{array}$ & 4 & 221 & $31.033 .888,87$ & 3.222 .056 \\
\hline $\begin{array}{l}\text { Downtown/ } \\
\text { Riofilme }\end{array}$ & 5 & 94 & $21.493 .471,47$ & 2.444 .120 \\
\hline $\begin{array}{l}\text { Universal / Europa } \\
\text { / Elo }\end{array}$ & 1 & 464 & $21.108 .060,56$ & 1.637 .032 \\
\hline Imagem/Riofilme & 1 & 347 & $20.038 .362,43$ & 2.176 .999 \\
\hline Imagem/Fox & 1 & 565 & $18.253 .649,24$ & 1.715 .763 \\
\hline Downtown/Europa & 1 & 360 & $7.066 .033,90$ & 848.733 \\
\hline Sony/RioFilme & 3 & 94 & $3.867 .869,36$ & 396.375 \\
\hline $\begin{array}{l}\text { Downtown/Sony/ } \\
\text { RioFilme }\end{array}$ & 1 & 195 & $3.099 .476,47$ & 353.690 \\
\hline Warner/Riofilme & 1 & 152 & $2.257 .084,00$ & 300.165 \\
\hline $\begin{array}{l}\text { Imagem/ } \\
\text { Conspiração }\end{array}$ & 1 & 208 & $1.026 .924,65$ & 80.335 \\
\hline $\begin{array}{l}\text { Moviemobz/ } \\
\text { RioFilme }\end{array}$ & 1 & 24 & $689.003,21$ & 71.056 \\
\hline $\begin{array}{l}\text { Film Connection/ } \\
\text { Imovision }\end{array}$ & 1 & 33 & $524.238,74$ & 38.073 \\
\hline
\end{tabular}

Tab. 5. Participação das alianças de distribuição nos filmes de maior bilheteria - 2009 - 2015.

Fonte: Elaborado pelos autores com base em dados do Observatório do Cinema e Audiovisual (www.oca.ancine.gov.br).

A análise da tabela 5 evidencia que as duas empresas nacionais que compõem o grupo 3 atuaram na codistribuição conjunta de 36 filmes de maior bilheteria. Além disso, a Downtown ainda codistribuiu mais dez filmes em outras alianças, principalmente com a Riofilme e Sony. A estratégia de lançamento dos filmes codistribuídos envolveu a utilização de um número elevado de salas na primeira semana de exibição. Para a Downtown e Paris, a média de salas ocupadas quando do lançamento dos filmes foi de 378. As duas empresas geraram o maior volume de bilheteria e público entre esses filmes.

As empresas do grupo 1, Fox e Imagem, tiveram uma menor presença nos filmes brasileiros de maior bilheteria nesse período, três filmes no caso da Imagem e apenas um da Fox. No entanto, o filme que foi codistribuído por Imagem e Fox foi o que teve presença no maior número de salas na primeira semana de exibição, 565. A estratégia de distribuição das majors envolve sempre o lançamento dos filmes em um grande número de salas de cinema na primeira semana de exibição. 
As empresas do grupo 2 tiveram pouca presença entre os filmes de maior bilheteria no período. Do grupo, a Sony foi a que teve mais presença, com seis filmes. Warner e Universal tiveram apenas um filme cada uma nessa lista. O filme codistribuído pela Universal foi lançado simultaneamente em 464 salas de cinema, o segundo maior valor entre as alianças encontradas.

Entre as seis empresas nacionais que compõem o grupo 4, apenas Riofilmes, Europa Filmes e Imovision tiveram filmes entre os de maior bilheteria no período. A Riofilmes participou da codistribuição de 24 filmes, com um número máximo médio de salas de 376. Isto aconteceu nas parcerias que fez com a Downtown e Paris. A Europa Filmes teve presença em seis filmes da lista, a maioria deles em parceria com a Riofilmes. Mas, ela participou da codistribuição de um filme com a Universal e a distribuidora brasileira Elo que foi lançado em 464 salas na primeira semana. Por fim, a Imovision fez uma parceria com a Film Connection e conseguiu incluir um filme nessa lista. No entanto, como se trata de empresas menores, o número de salas na primeira semana foi somente 33.

As empresas do grupo 5 tiveram a presença de quatro delas entre os filmes de maior bilheteria no período. Os filmes em que tiveram maior sucesso foram codistribuídos com empresas dos outros grupos. A Elo participou de aliança com Universal e Europa em um filme. A Film Connection fez parceria com a Imovision também em um filme, a Conspiração atuou em conjunto com a Imagem em um filme, e a Moviemobz, também em um filme, com a Riofilmes.

\section{Considerações finais}

A codistribuição de filmes brasileiros é uma estratégia de negócios com presença crescente nos últimos anos no mercado brasileiro. Embora, o número de empresas distribuidora que realizam parcerias para codistribuir filmes nacionais seja pequeno, pouco menos de 15\%, esta forma de atuação tem gerado resultados positivos às empresas.

A análise das informações permitiu identificar cinco formas distintas de atuação estratégica na codistribuição do cinema brasileiro com características distintas. Sejam grandes ou pequenas, brasileiras ou estrangeiras, novas entrantes ou empresas estabelecidas no mercado a mais tempo, a codistribuição vem se estabelecendo como uma prática importante para o sucesso das distribuidoras.

Baseado apenas em dados secundários, este estudo apresenta uma limitação de não poder evidenciar claramente as motivações que levaram essas empresas a envidarem esforços de codistribuição. Nesse sentido, estudos futuros podem explorar esse tema, por meio de entrevistas com os gestores das empresas que fazem codistribuição no mercado do audiovisual brasileiro.

Outra limitação do estudo se relaciona ao fato de que não foram obtidos dados sobre o desempenho econômico-financeiro das empresas analisadas. Embora os números 
agregados de público e renda de bilheteria sejam potenciais indicadores de uma contribuição significativa da codistribuição para o resultado empresarial das empresas, é necessário aprofundar esta análise com o objetivo de identificar a contribuição da codistribuição para a lucratividade das distribuidoras de cinema no Brasil. Essa é uma outra linha de investigação que pode ser explorada no futuro.

Fernando Antonio Prado Gimenez é especialista em cinema e doutor em Administração. É professor titular do Departamento de Administração Geral e Aplicada da Universidade Federal do Paraná e editor da Revista Livre de Cinema.

fapgimenez@gmail.com

Daniela Torres da Rocha é doutora em Administração pela Pontifícia Universidade Católica do Paraná, com pós-doutorado em Administração junto ao Programa de Pós-Graduação em Administração da Universidade Federal do Paraná.

danitorres.rocha@gmail.com

\section{Referências}

ANCINE - Agência Nacional do Cinema. Anuário Estatístico do Cinema Brasileiro. Brasília: Agência Nacional de Cinema, 2015.

AUTRAN, A. O cinema brasileiro contemporâneo diante do público e do mercado exibidor. Significação, v. 32, n. 36, p. 119-135, 2009.

BAHIA, L. Discursos, políticas e ações: processos de industrialização do campo cinematográfico brasileiro. São Paulo: Itaú Cultural; Iluminuras, 2012. 228 p.

BORGES, D. dos S. A produção cinematográfica brasileira (1995-2014) e o atual modelo de políticas públicas para o cinema nacional. Revista EPTIC, v. 17, n. 3, p. 178-200, 2015.

ELIASHBERG, J.; ELBERSE, A.; LEENDERS, M. A.A.M. The motion picture industry: critical issues in practice, current research, and new research directions. Marketing Science, v. 25, n. 6, p. 638-661, 2006.

ESTEVINHO, T. A. D. Cinema e política no Brasil: os anos da retomada. Aurora, n. 5, p. 120-130, 2009. HAIR JR., J. F. et al. Análise multivariada de dados. 5. ed. Porto Alegre: Bookman, 2005.

IKEDA, M. O Mercado Cinematográfico Brasileiro e a Aliança entre o Global e o Local. Revista Geminis, v. 3, n. 2, p. 69-82, 2012.

MATTA, J. P. R. Políticas públicas federais de apoio à indústria cinematográfica brasileira: um histórico de ineficácia na distribuição. In: Meleiro, A. (org.) Cinema e Mercado, São Paulo: Escrituras Editoras, 2010, p. 37-52. 
MICHEL, R. C.; AVELLAR, A. P. Indústria cinematográfica brasileira de 1995 a 2012: estrutura de mercado e políticas públicas. Nova Economia, v. 24, n. 3, p. 491-516, 2014.

PANGARKER, N.A.; SMIT, E.V.D.M. The determinants of box office performance in the film industry revisited. South African Journal of Business Management, v. 44, n. 3, p. 47-58, 2013.

RUY, K. dos S. Estratégias e apostas da indústria cinematográfica brasileira contemporânea. Famecos, n. 22, p. 69-76, 2009.

SCOTT, A. Hollywood and the world: the geography of motion-picture distribution and marketing. Review of International Political Economy, v. 11, n. 1, p. 33-61, 2004.

SIMIS, A. Economia política do cinema: a exibição cinematográfica na Argentina, Brasil e México. Versión. Estudios de Comunicación y Política, n. 36, p. 54-75, 2015.

YOSHINO, M. Y.; RANGAN, U. S. Alianças estratégicas. São Paulo: Makron Books, 1996.

Artigo recebido em 20 de dezembro de 2016 e aprovado em 08 de fevereiro de 2017. 